\title{
Theoretical Logic for Reform of Public Service Supply in Rural Areas in China
}

\author{
Siwei Wang \\ School of Literature, Law and Economics \\ Wuhan University of Science and Technology \\ Wuhan, China 430065
}

\author{
Zhongyi Tang \\ School of Literature, Law and Economics \\ Wuhan University of Science and Technology \\ Wuhan, China 430065
}

\begin{abstract}
The Fifth Plenary Session of Eighteenth Central Committee advanced five concepts for development namely "'innovation, coordination, green, opening and sharing" in 2015 in order for realizing the goal of building an affluent society, meanwhile, the concept of sharing development shows a new direction and way for the affluent society, emphasizing the coordinated development and sharing development also bring new opportunities and requirements for the reform of public service supply in rural areas. Therefore, it has become an urgent key problem to be solved on how to clarify concepts of public service in rural areas, discuss reasons for the reform of public service supply and push the reform of public service supply so as to improve the efficiency of public service supply in rural areas.
\end{abstract}

Keywords-public service in rural areas; supply reform; theoretical logic

\section{INTRODUCTION}

In recent years, China's governments has been devoted to realizing the equality to enjoy basic public services by citizens in urban and rural areas, the public service supply in rural areas is also being strengthened, and its roles in promoting agricultural production and improving people's livelihood have appeared initially. On the urban and rural income level, by the end of the year 2015, the disposable income of rural residents per capita totaled 11,422 yuan, up $8.9 \%$ over the previous year, the disposable income of urban residents per capita totaled 31,195 yuan, up $8.2 \%$ over the previous year, and the net income of residents per capita in rural areas rose from 6,977 yuan in 2011 to 10,772 yuan in 2015. [1] The income of farmers increased quickly, besides, and the growth rate of disposable income of farmers per capita is higher than that of urban residents. Compared with urban residents, the rural residents also have the gaps narrowed gradually in basic education, basic medical care and healthcare.

However, seen as a whole, the inadequate supply of public services in rural areas in the country coexists with the serious imbalance in the supply and demand structure. the imperfect

About the authors: Siwei Wang, MPA of School of Literature, Law and Economics, Wuhan University of Science and Technology. Zhongyi Tang, professor, postgraduate supervisor and president of School of Marxism, Wuhan University of Science and Technology.

Topic Source: Important Project of Hubei Education Department: Research on Public Service System and Operation Mechanism on the Basis of Construction of New Villages and Harmonious Society (EJSZBH[2014] File 6; No: 201412 supply system coexists with low supply efficiency, and the imbalance of public service supply between urban areas, rural areas and different people has not been changed thoroughly, and the dualistic structure in urban and rural supply, a restricting factor, still exist. [2] Obviously, it is far to meet the requirement newly advanced for sharing development, which highlights the necessity and importance for the reform of public service supply in rural areas in the country. In the opinion of the author, the reform of public service supply in rural areas will be eventually turned to the theory of "why to reform, what for reform and how to reform". Therefore, it will be greatly valuable to explore reasons for reform of public service supply in rural areas, how to push the reform process so as to improve the overall efficiency of public service supply in rural areas.

\section{THEORETICAL BASIS FOR REFORM OF PUBLIC SERVICE SUPPLY IN RURAL AREAS IN THE COUNTRY}

\section{A. Definitions}

Public goods was earliest defined by Lindahl, afterwards, it was explained by economists to form different views. Currently the expounding of the economist Samuelson P. is the mostly acceptable in the field, namely the public goods means that all enjoy in common in the sense that each individual's consumption of such a good leads to no subtractions from any other individual's consumption of that good, having two properties as non-excludability and non-rivalry.[3]

As for the definition of public service and its relations with public goods, currently there are three views basically: first, mutual complementation. Based on the form of yield, according to the space and time for production and consumption, it is divided into tangible and intangible. Public goods separable is called tangible, public service inseparable is called intangible. Based on it, public facilities belong to public goods, education and pension and so on belong to public service; Second, equivalence. Based on the externality, seen from two properties of public goods, public goods is equivalent to public service; Third, inclusive. Seen from existing researches, it is still not unified by the academic field. Some scholars, considering the nature and functions of government agencies, think that one of the important functions of government agencies is to provide public goods and 
services to the public so as to meet the needs of the public in production, living and development. The meaning of public service here is generalized, which not only covers public goods, but also include the products and public service which have no complete property of public goods but the governments are responsible to provide, some think that the scope of public goods is greater than public services.

This article favors the second and the third views, namely based on the externality, public goods and public services are basically the same, but different in some details: First, public goods are specific yet public service is relatively abstract; second, the public service has a certain concept of value, which is related to basic rights of the people, yet the public goods are not always like it; Third, public services emphasize particularly on indifferent supply and enjoyment, yet public goods is not the case, especially the crowded public goods, which sometimes shall be paid for enjoyment. In this article, the public service in rural areas is defined to meet the public demands of rural residents, and the goods and service they should enjoy fairly and universally shall include not only the pure public goods and semi-public products but also the goods and service to be provided on the basis of moral, social stability and development. In the meantime, according to the yield form and purpose, the public service in rural areas is divided into four kinds as living, production, development and government affairs.

\section{B. About Supply Side Structural Reform}

The concept of supply side reform was put forward firstly by General Secretary Xi Jinping, clearly pointing out that "while moderately expanding the total demand, strengthen the supply side structural reform, improve the quality and efficiency of the supply system and enhance the power for sustainable economic growth". [4] Since then, national leaders have repeatedly stressed this concept in various occasions, it needs to clarify that though the current "supply-side reform" in China is similar to the western theory of supply-side economics, yet due to the difference in national conditions and development environment, the policies have to differ. The core of "supply-side reform" in the country is to adjust the economic structure and transform the pattern of economic development, and improve the productivity of all factors through raising the adaptability and flexibility of the supply structure.

In order for the public service supply in rural areas, it needs to carry out the concept of coordinated development and sharing development, realize the adjustment and change of supply pattern of the public service supply structure in rural areas, and further achieve the optimal allocation of public service resources in rural areas, and ensure the efficiency of public service supply. Just like the core spirit of "supply-side reform" advocated by General Secretary Xi Jinping, in order to solve the deep-level problems of public service supply in rural areas, it is necessary to make greater efforts to promote the reform of public service supply structure in rural areas, making the supply system better meet the demand structure.

\section{Concept of Development Sharing}

The Fifth Plenary Session of Eighteenth Central Committee advanced the concept of sharing development, and emphasized "in order for sharing development, it needs to insist on the development for the people, relying on the people and shared by the people, establishing efficient systems and making all the people obtain more during the construction and sharing development"[5] The concept of sharing development, having a profound meaning, is an innovation in the concept of social and economic development, and a basic principle and important guide to observe so as to drive the economic development in the new situation.

Seen from the coverage, it shall be inclusive of all the people, first of all, it shall be inclusive of all classes, ethic groups and regions; second, the sharing development does not mean no difference; finally the gap for development enjoyment shall not be over wide and must be well controlled.

Seen from the contents for enjoyment, it is inclusive of all aspects, but not a simple enjoyment of development achievements, it shall be made clear that the economic development achievements are basis only, and the core contents shall include rights for development, opportunities for development and development achievements.

Seen from the ways for development, it is a co-construction and sharing. The co-construction is a base, the sharing needs the participation of all the people for construction. So it needs to regard the principal status of the people, collecting the wisdom of the people.

Seen from the development process, it is a progressive sharing. It must be seen that due to the reasons as economic development level, historical factors, shortage of resources and so on, the imbalanced development between urban and rural areas is still comparatively prominent, the sharing development still has a wide gap from the new demands and expectations of the people. Therefore, we must keep a solid and ordered improvement of the people's livelihood.

\section{Necessity for Reform of Public Service Supply in Rural Areas}

1) An efficient response to reform of supply-side structure: Seen from the logic of reform, no doubt that the reform of public service supply in rural areas is an efficient response to the reform supply-side structure, and it plays a key role in promoting the construction of an affluent society by and large.

First, though previous reforms in rural areas before the construction of new villages were pushed continuously yet most were aiming at single project, failing to change fundamentally the original supply system of public service in rural areas, besides, the dualistic supply system between urban areas and rural areas and the reform of public service supply separating urban areas from rural areas obviously influence the process of reform in rural areas. Second, after the opening-up and reform, the reforms in the productivity and relations of production have brought strong impacts to the traditional public service supply system and mechanism in rural areas, which has not only highlighted its malpractice but also caused the sharp contradiction in rural areas, during the transformation 
of social control, the public service supply in rural areas have different characteristics such as transition, pluralism and irregularity, it is urgent to further the reform of public service supply in rural areas.

2) An inevitable selection and urgent task to deepen understanding of national conditions: Seen from the current national situation, the "farmer, agriculture and village" problem is related to not only the stability and economic and social development in rural areas, but also the goal of building an affluent society, so it is necessary to strengthen the root and the base and take careful measures for settlement.

In recent years, the construction of public service has been expanding and the agricultural production has made a great progress and the living conditions of farmers have been greatly improved. However, seen as a whole, due to the factors as history and systems, the public service supply in the country is still kept in a large gap in quantity and quality, there exist serious imbalance in structure and low efficiency, and the public service system in rural areas has not been established or it is still called imperfect. It can be said that the deepening reform of the public service supply in rural areas has been ready without hesitation.

3) A power for sharing development and its significance: Analyzed from the interests of farmers, they belong to a weak class when enjoying the development achievements, to balance the benefits between urban and rural and increase the happiness and benefits of farmers have been depending increasingly on the reform of public service supply in rural areas. Thus it requires the governments to accelerate the reform of dualist supply system and mechanism of public services in urban and rural areas, value and solve the problem of shortage in public service supply and imbalance of supply structure in rural areas, promote the equalization of public service supply and enjoyment in urban and rural areas, reduce the gap of urban and rural residents to enjoy basic public service, enabling farmers to benefit and ultimately realize the sharing development.

\section{PRINCIPLE FOR REFORM OF PUBLIC SERVICE SUPPLY IN RURAL AREAS AND MAIN CONTENTS}

\section{A. Principle for Reform of Public Service Supply in Rural Areas}

1) Fair and just: In order to keep it fair, public goods and services shall be provided to urban and rural residents with the same quantity and quality, reducing the gap between regions for enjoyment. Continuously deepen the reform of public service supply in rural areas, greatly push the development of social undertakings in rural areas, further unblock channels for urban and rural exchanges, make public service resources flow to the grass-root governments, poor rural areas and weak groups in rural areas so as to rationally distribute resources and achieve balanced development, gradually form a completely fair public service supply system covering every corner in rural areas, improve the public service supply level in rural areas and enable farmers to really enjoy the achievements of economic construction and cultural development.

In order to keep it just, during the public service supply in rural areas, the procedures and results must be kept just, and the suppliers of public service in rural areas shall be able to compete rationally in a fair and just environment.

2) Insist on the government-led and multiple supply: Insist on the government-led and multiple supply, according to the class and property of public service, the government shall take the lead for supply, encouraging markets, non-profit social organizations and individuals for participation.

The government should know what to do and what no to do. First of all, it should provide public services in rural areas within the legal responsibilities. And it should provide nationwide and trans-regional public services in rural areas, which are related to the interest of the whole nation, and local government should provide regional public services in accordance with the jurisdiction and benefit scope; second, it should establish rules and strengthen the control and create a favorable environment, coordinate suppliers so as to promote and improve the public service supply in rural areas; finally, it should strengthen the access to and exit from markets, carry out economic or social control, urge and supervise the production and supply of public services.

3) Insist on gradual advancement and special push: Grasp the principle of gradual advancement together with special push. First, it must be seen that the reform of public service supply cannot be accomplished in an action, and it has to be done from point to line, line to surface so as to expand the service scope, increase the service recipient and improve the service quality. Second, guided by the integration of urban and rural areas, clarify by stages what are urgent and key and what not, make a special push in the supply content, give priority to meet the most basic needs of farmers for survival, improve the basic agricultural production, basic medical and health care, etc. For example, in poor mountainous areas in a remote distance, the basic problem is how to solve the foods and livelihood of farmers, so the supply of public service as productive infrastructures, basic education and social security is to meet the most urgent needs of farmers; Ye for the developed areas, the comprehensive layout and public area in the areas may be much valued.

4) Insist on reform, innovation and overall consideration: Observe the principle of reform, innovation together with overall consideration. Based on the equal enjoyment of basic public service for urban and rural residents, push the reform of financial systems in counties and towns, and raise the capabilities of grass-roots governments in public service. Establish an overall planning for urban and rural residents to equally enjoy basic public service, clearly distribute the duties and powers of governments of all levels in order for financial arrangement, and build an equal supply led new public fiscal systems. Especially focus on the transformation of functions of grass-roots governments, changed to a service orientated government. As the first level government which is the closest to farmers, the town governments should improve the 
awareness of providing public service in rural areas, renew work concepts and attitudes.

\section{B. Main Contents of the Reform of Rural Public Service Supply in Our Country}

The reform of rural public service supply should aim at the public demands of peasants, draw a clear distinction between the primary and the secondary and gradually carry out at different stages and regions. It suggests that the formulation and optimization of the supply order should base on the degree of satisfaction and requirements and adhere to the principle of "centering on the requirements and considering the satisfaction".

1) Pay attention to the "high demand" and improve the public service of life: Governments at all levels shall give priority to the service items of "high demand". It is necessary to improve the public service of life, strengthen the infrastructure construction and improve the public sanitary condition in rural areas, help the household enjoying the minimum living guarantee. They should seek welfare and exclude the difficulty and anxiety of people.

Based on consolidating the existing working results, continue to increase input and endeavor to improve the rural basic public service level. For example, in the basic medical service and health care, strengthen the management of medicine market and the construction of the medical care group, gradually update the medical facilities and improve the medical level. In the basic education, increase input of capital and teachers in the senior high school stage, increase the number and category of rural public kindergartens and strengthen the construction of low-performing schools, intensify the communication between urban and rural teachers. Besides, we should also balance the teacher allocation, update the teaching facilities and improve teachers' morality and quality in rural schools to narrow the educational gap.

2) Develop the productive public services based on the physical truth: Government sectors shall selectively provide and improve the productive public services in accordance with the actual needs and the financial resources in local areas. In the agricultural production, because of the different geographical conditions and agricultural production techniques in different rural areas, the government shall adjust measures to local conditions in providing public services. According to the physical truth reflected by the agricultural grassroots cadres and the reality of our country, intensify the technical support for the poor rural areas especially the mountainous areas, old liberated areas and minority areas with backward economic development, strengthen the implementation of agricultural supportive policies, so as to help them to increase both production and income and overcome poverty and achieve prosperity.

3) Highlight the characteristics and improve the developmental public services: Governments at all levels shall provide the developmental public services and highlight local characteristics according to the economic and social development. For example, for towns with many industrial projects, they should further supervise the key enterprises of pollutants discharge reduction, take special actions of environmental protection to prevent and control the sudden environmental pollution accidents; for towns with rapid economic development, they should liberalize the condition of loan from financial institutions and make it more convenient for rural residents to take out a loan; for towns with a good situation of public security, eliminate potential safety hazard and improve the rural residents' sense of traffic safety and legal awareness of self-protection; for towns with sound information network, timely deliver the market information of agricultural products, labor service information and weather information through the information network. For areas without the above conditions or without the sound conditions, it is necessary to create conditions and offset the deficiencies.

4) Emphasize the sharing and promote the public services of government affairs: The promotion for the rural public services of government affairs needs the top-level design and coordination. The management level of grassroots governments can be improved through adhering to the "convenient, shared, transparent and safe" principle, building and improving the "one-stop" service platform, building up database of rural government affairs service and starting from the reform of "internet plus government affairs service" according to the new requirements of strengthening the service and improving the effectiveness. Specifically speaking, it includes: grasp the key point, standardize the government review and approval, reform the "one door, one network" government service mode, realize the one door plus one network mode through depending on counties and towns as well as online business hall, to provide the around-the-clock government affairs service of zero distance. Manage the service windows and realize "many things can be handled at one window"; deal with more government affairs on the internet and improve the normal service mechanism; listen to the new demands of rural residents and build up the module of archives information, dynamically reflecting the problems and the solutions to it as well as improving the rural residents' satisfaction degree.

\section{SIGNIFICANCE OF THE REFORM OF RURAL PUBLIC SERVICE SUPPLY IN OUR COUNTRY}

\section{A. Help to Solve Issues of Agriculture and Other Social} Problems Brought by the Urban-Rural Dualism, So As to Realize the All-Round Well-Being for People with Shared Development

Since the reform and opening up, we have achieved results in narrowing the urban-rural gap. Fundamentally, it doesn't involve the urban-rural dualism. Some systems, policies and ideas adverse to the rural development still exist. The urbanrural gap is still a "big and difficult" problem affecting the continuous growth of the economy and a wide gap in front of the realization of building moderately prosperous society. The rural public service is the weakness of rural areas and the vital part of issues of agriculture. 
Deficiencies of rural public service will inevitably have negative effects on the "agriculture, farmer and rural area". On one hand, the benefits of agriculture and rural area cannot be guaranteed; on the other hand, the public service resources gather in cities, so that the state revenue cannot effectively cover the whole rural area. The rural public service supply is insufficient. The income of farmers grows slowly at the meantime the rural public service as well as the public infrastructure construction is backward. We cannot neglect these problems.

The reform of rural public service supply helps to solve issues of agriculture and other social problems brought by the urban-rural dualism, narrow the gap between supply and enjoyment of public service in urban and rural areas, offset the rural public service, so as to realize the all-round well-being for people with shared development.

\section{B. Help to Lay a Solid Foundation of System and Deeply Implement the Concept of "Shared Development"}

The insufficient rural basic public service supply and the great gap of public services between urban and rural areas originate from the different public service systems of them. Because of the different basis of economic and social development, it allows the existence of certain gap between the urban and rural public services, but wide gap is not allowed. The concept of "shared development" highlights the equality of all stratum on sharing the development achievements, pursuing the unification and reflecting the fair and shared value appeal.

The reform of rural public service supply bases on the bottom-line thinking and consider roundly according to the physical truth and requirements. It is necessary to formulate more effective systems to promote the shared development of rural areas, helping to further promote the marketization process of rural areas, set up rural pubic service system and implement the economic and social policies to promote the urban and rural unification. In order to narrow the gap between urban and rural residents in enjoying the public infrastructure, basic medical care and health care, lay a solid foundation of system, ensure the equality between urban and rural residents in the basic rights of existence and development, which is the in-depth implementation of the "shared development" concept.

\section{It Is the Correct Understanding and Scientific Grasp of the Law on Governance, Helping to Maintain the Ruling Status of the Party and Promote the Socialist Modernization}

According to the rural reforms in recent years, both the opinion that "center the national infrastructure construction and the development of social undertaking on the rural areas, promote the new rural construction, poverty relief and development and roundly improve the rural production and rural conditions" proposed on the Report to the Eighteenth National Congress of the Communist Party of China, and the shared development concept proposed on the Fifth Plenary Session of the 18th Central Committee of the Communist Party of China require to start from the most direct and realistic problems of benefits that the public concern about most, improving the ability and level in building and sharing the public services. The general secretary $\mathrm{Xi}$ Jinping emphasizes it is distinctly important to promote the structural reform especially on the supply side, which is the "nose of an ox" for the main development line of the 13th Five-Year Plan. Obviously, the policies related to the rural reform are similar and reflect the correct understanding and scientific grasp of the law on governance, helping to maintain the ruling status of the party and promote the socialist modernization.

\section{CONCLUSION}

The reform of rural public service supply is conducive to the social stability of rural areas, the economic development of agriculture and the improvement of farmers' well-being. The development of "agriculture, farmer and rural area" cannot do without the improvement of rural public service supply. The situation will be worse if we don't offset the "deficiency". Therefore, it is necessary to implement the reform that "pull one hair and the whole body is affected". The author believes, with the deepening of reform, the construction of system and the increase of input, the structure of public service will be optimized and the level will be improved. It will inevitably promote the great progress on building moderately prosperous society of our country as well as the achievement of results in coordinated and shared development and benefit all the people.

\section{REFERENCES}

[1] Statistical Communique on the 2015 National Economic and Social Development, State Statistics Bureau [N], Feb.29, 2016.

[2] Gao Ren. Research on the Reform of Rural Public Service Supply [J], Truth Seeking, 2014(3)

[3] Samuelson.P. The Pure Theory of Public Expenditure. Review of Economic and Statistics, 1954.

[4] Strengthen the Structural Reform on the Supply Side, Improve the Quality and Efficiency of the Supply System, people.cn [N], Mar.22, 2016

[5] Communique of the Fifth Plenary Session of the 18th Central Committee of the Communist Party of China, CAIXIN.COM [N], Oct.29, 2015

[6] Hu Angang, Zhou Shaojie. Structural Reform of the Supply Side--Adapt to and Lead the New Normal of Chinese Economy [J], Journal of Tsinghua university (Philosophy and social science edition), 2016(2)

[7] Zhang Shuo, Gao Jiujiang. Analysis on Xi Jinping's Political Economy [J], Journal of Dalian Official, 2016(3). 